\title{
Fragaria orientalis Losinsk in Yakutia: populations, selection and breeding prospects
}

\author{
Valentina Belevtsova ${ }^{1 *}$, and Olga Sorokopudova ${ }^{2}$ \\ ${ }^{1}$ M.G. Safronov Yakut Research Institute of Agriculture, 677001, Republic of Sakha (Yakutia), \\ Yakutsk, Russia \\ ${ }^{2}$ Russian State Agrarian University - K.A. Timiryazev Moscow Agricultural Academy, 127550, \\ Moscow, Russia
}

\begin{abstract}
The state of populations, selection and prospects of breeding in the genus Fragaria L. in the conditions of Yakutia are considered in the present contribution. The object of the study is an almost unexplored species of eastern strawberry - Fragaria orientalis Los., formed under the conditions of severe natural selection and having a high ecological adaptability to local natural and climatic conditions.
\end{abstract}

\section{Inthjduction}

The center of origin and initial development of the genus Fragaria L. is considered to be East Asia [1-3]. Wild species of the genus Fragaria L., significantly superior to cvs. F. ananassa Duch, are used for winter hardiness, but most of them, being sources of important properties and economically valuable traits, are not used in strawberry breeding due to the weak knowledge of the genetic potential [3]. Not sufficiently studied in the conditions of Yakutia is the eastern strawberry Fragaria orientalis Los., formed under conditions of severe natural selection and having a high ecological adaptability to local natural and climatic conditions. It is widely spread over the territory of Central Yakutia. High frost resistance, immunity, productivity, unpretentiousness, excellent taste and aroma of fruits are the main advantages of this species are of undoubted interest for breeding in extreme conditions. The scientific research on the introduction and selection of strawberries in the M. G. Safronov Yakut Research Institute was started in the mid-90's [6-7].

The aim of the research is to study the populations of eastern strawberries to create local varieties that combine a high level of productivity with the adaptability to a complex of biotic and abiotic environmental factors.

\section{Conditions, materials and methods}

The work was performed at M. G. Safronov Yakut Research Institute of Agriculture. The climatic conditions of Central Yakutia are the least favorable for the cultivation of garden strawberries, since the winter period is characterized by extreme temperatures and low

\footnotetext{
* Corresponding author: vibvega@yandex.ru
} 
snow cover. The summer period is characterized by aridity with very high temperatures and their sharp fluctuations, and strong winds are often observed. The annual temperature differences at the absolute minimum and maximum reach $102^{\circ} \mathrm{C}$. In July, the average temperature is 18.7 , the maximum is $38.0^{\circ} \mathrm{C}$, the average temperature in January is $-43.3^{\circ} \mathrm{C}$ and the minimum is $-64^{\circ} \mathrm{C}$. The annual precipitation is $247 \mathrm{~mm}$ [8].

The research material was the strawberry species $F$. orientalis Los., which was studied in the field. The main records and observations were carried out according to the generally accepted program and methodology of berry crops cultivar study [9].

\section{Results of investigations}

The rational direction of using Fragaria orientalis Los. is its hybridization with the most promising varieties of garden strawberries that combine a complex of economically valuable traits [10-11]. During the testing period of 1999-2020, the most extreme temperature values of air $-52,-55^{\circ} \mathrm{C}$ and soil, at the root layer depth of $0-20 \mathrm{~cm},-25.6^{\circ} \mathrm{C}$, taking into account the $22 \mathrm{~cm}$ snow cover height in January, were noted.Outside the ecological range of the original forms, when transferred from the local flora, under the conditions of introduction, the eastern strawberry acclimatizes very quickly, within 2 years, and in its development significantly exceeds the wildspecies. In cultivated forms, the bush of the second year of fruiting is powerful (up to $35 \mathrm{~cm}$ or more) with a leafy and vertical habitus. The beginning of ripening is July 1-3, which is 10-14 days ahead of wild forms. The average yield per bush is $165.8 \mathrm{~g}$, the maximum is more than $200 \mathrm{~g}$, the number of peduncles is 54.7, generative organs - 324.8 and whiskers -112.5 . The weight of berries at the first harvest exceeds wild-growing ones by more than 8 times (2.5-3.5 g), and the number of ripe berries is incomparably higher and can reach from 150 to 220 pieces per bush.

It was also established during the studies that the ecotype of $F$. orientalis Los. is of exceptional value for breeding, because it has a complex of important features, due to which it was possible to significantly increase the breeding efficiency during interspecific crosses of strawberry species, including with F. $\times$ ananassa Duch. In Table 1 are the characteristics of the interspecific cross-combinations of $F . \times$ ananassa Duch. $\times F$. orientalis, from which unique varieties of strawberries for Yakutia were obtained.

Table 1. Characteristics of interspecific strawberry cross-combinations.

\begin{tabular}{|c|c|c|c|c|c|c|c|}
\hline \multirow[t]{3}{*}{$\begin{array}{c}\text { Cross-combinations, } \\
\mathrm{cv} .\end{array}$} & \multirow{2}{*}{\multicolumn{2}{|c|}{$\begin{array}{l}\text { Temperature minima } \\
\text { at the depth of } 20 \mathrm{~cm} \\
\text { for }\end{array}$}} & \multirow[t]{3}{*}{$\begin{array}{l}\text { Yield, } \\
\text { cntn/ha }\end{array}$} & \multicolumn{2}{|c|}{ Berry mass, $\mathrm{g}$} & \multirow{3}{*}{$\begin{array}{c}\text { Content } \\
\text { of } \\
\text { vitamin } \\
\text { C, } \%\end{array}$} & \multirow{3}{*}{$\begin{array}{l}\text { Nasting } \\
\text { eval., } \\
\text { scores }\end{array}$} \\
\hline & & & & \multirow{2}{*}{ average } & \multirow[t]{2}{*}{$\max$. } & & \\
\hline & air & soil & & & & & \\
\hline $\begin{array}{l}\text { 1. Naidena dobraya } \\
\times \text { F.orientalis Los. } \\
\text { Bersenevskaya }\end{array}$ & -55.0 & -25.6 & 71.7 & 5.6 & 11.2 & 105.5 & 5.0 \\
\hline $\begin{array}{l}\text { 2. Tanyusha } \times \\
\text { F.orientalis Los. } \\
\text { Sadovo-spasskaya }\end{array}$ & -55.0 & -25.6 & 94.9 & 8.2 & 26.7 & 109.8 & 5.0 \\
\hline $\begin{array}{l}\text { 3. Bohema } \times \\
\text { F.orientalis Los. } \\
\text { Vladyka Zosima }\end{array}$ & -53.3 & -25.6 & 79.8 & 15.4 & 46.4 & 124.5 & 4.9 \\
\hline
\end{tabular}

As a result of the conducted research, we give the characteristics of new strawberry varieties for the harsh conditions of Yakutia:

Sadovo-spasskaya (Tanyusha $\times$ Fragaria orientalis Los.) is a variety of medium ripening and universal purpose. The bush is strong-growing and vertical, the leaves are dark 
green, large in size and with a strong shine. The berries are tupoconic and medium-sized ; there is no neck, the surface is slightly uneven, bright red, uniform and with a shine. The average weight of berries from the first collections is 8-10 g (maximum $26.7 \mathrm{~g}$ ). Achenes are yellow, located above the skin, and the zone without achenes is narrow. The flesh is red, and the cavity is narrow. The content of sugars is $10.3 \%$, acids $-1.3 \%$ and ascorbic acid $94.2 \mathrm{mg} \%$. The taste is harmonious and with a pronounced nutmeg aroma. The tasting score is 5.0. The yield is $9.5 \mathrm{t} / \mathrm{ha}$ and using high agricultural technology, it is more than $15 \mathrm{t} / \mathrm{ha}$. The variety is non-remontant and self-fertile. Its winter hardiness is high. It is resistant to powdery mildew and to all types of spots.

Bersenevskaya (Naidena dobraya $\times$ Fragaria orientalis Los. is a variety of early ripening and universal purpose. The bush is medium-sized and spreading, with green leaves and medium-sized. The berries are heart-shaped. There is no neck. The surface is smooth or slightly uneven, of uniform red color and with a strong shine. The average weight of berries is 4-5 g (maximum $11.2 \mathrm{~g}$ ). Achenes are yellow, located above the skin. The zone without achenes is narrow. The flesh is orange-red and the cavity is medium. The content of sugars is $9.8 \%$, acids $-1.2 \%$, ascorbic acid $-75.6 \mathrm{mg} / 100 \mathrm{~g}$. The taste is very harmonious with a strong nutmeg aroma. The tasting score is 5.0. The yield is $9.5 \mathrm{t} / \mathrm{ha}$ and, using high agricultural technology, it is more than 10 t/ha. Its winter hardiness is high. It is resistant to powdery mildew and to all types of spots. The variety is non-remontant and self-fertile.

Vladyka Zosima (Bohema $\times$ Fragaria orientalis Los.) is a variety of early ripening. The variety is non-remontant, self-fertile and of universal purpose. The bushes are stronggrowing, and the leaves are green with a bluish shade. The berries are large, red-colored, wide-conical, without a neck, sometimes comb-shaped, with a shiny skin and an average weight of $15.4 \mathrm{~g}$, (maximum $52.3 \mathrm{~g}$ ); by the end of the season the berries are significantly smaller (less than $10 \mathrm{~g}$ ). Achenes are yellow, numerous and are located above the skin. During the ripening period, under weather conditions with a predominant predominance of cloudy days, very large fruits may have incomplete ripening of the tip. The content of sugars is $10.0 \%$, acids $-2.2 \%$, ascorbic acid $-124.5 \mathrm{mg} / 100 \mathrm{~g}$. The berries taste is sweet and sour, with a harmonious nutmeg aroma. The flesh is red, juicy and tender. The cavity is absent or small. The tasting score of fresh berries is 4.9 points. The average yield is $8.0 \mathrm{t} / \mathrm{ha}$ and, using high agricultural technology, it is more than $15 \mathrm{t} / \mathrm{ha}$. Its winter hardiness is high. Drought resistance and heat resistance are average. The resistance to diseases and pests is average

A distinctive feature of the Vladyka Zosima variety is high productivity in the first year of fruiting, very early ripening (the third decade of June), large fruit-the weight of fruits at the first harvest is more than $30 \mathrm{~g}$, a long period of fruiting (until August 15) and a high content of vitamin C. A significant disadvantage of the variety is low transportability due to the very delicate consistency of berries.

High stability and productivity over the years was noted in the Sadovo-spasskaya variety. The early ripening period, high winter hardiness and high taste qualities are characteristic for the Bersenevskaya variety. The Vladyka Zosima variety is distinguished by its early ripening period, high productivity in the planting year and a long fruiting period.

As a result, from 1999 to 2020, among the prolific seedlings, a variety of forms with different types and terms of fruiting, different yields and weight of fruits, diverse in shape and taste, whisker-forming and whiskerless, the invariable selection criterion of which is high winter hardiness, was obtained. New selected forms are promising for the use in strawberry breeding in the conditions of Yakutia.

\section{Conclusions}


In the conditions of the Republic of Sakha (Yakutia), the populations of eastern strawberries were studied, the most promising forms were selected, and varieties Sadovospasskaya, Bersenevskaya and Vladyka Zosima, with a complex of economically valuable characteristics, were created.

The high stability and productivity over the years of the Sadovo-spasskaya variety was noted. The early ripening period, high winter hardiness and high taste qualities are characteristic for the Bersenevskaya variety. The Vladyka Zosima variety is distinguished by its early ripening period, high productivity in the planting year and a long fruiting period.

The result of research from 1999 to 2020 was the creation of diverse seedlings with different types and terms of fruiting, yield and weight of fruits, diverse in shape and taste, whisker-forming and whiskerless and with high winter hardiness for further breeding.

\section{References}

1. N. B. Sukhareva, On the possibility of using Fragaria orientalis Los. in breeding, Cultivated plant cytology and genetics (Novosibirsk, 1967)

2. N. B. Sukhareva, Siberian and Far-Eastern strawberries. Apomixis and its significance for evolution and breeding (Novosibirsk, Nauka, 1976)

3. A. A. Zubov, Theoretical bases of strawberry breeding, Michurinsk, I.V. Michurin AllRus. Res. Inst. of Fruit Plant Gen. and Breed., 44 (2004)

4. D. F. Petrov, N. B. Sukhareva, Distant hybridization and apomixis in the genus Fragaria and their significance for strawberry breeding in Siberia, Agric. Biol j., 2 (1983)

5. V. I. Belevtsova, A. A. Mironova, V. N. Sorokopudov, Sci. Bullet. of Belgorod State Univ, Series of Natural Sciences, 9, 15/1 (2011)

6. T. I. Volkova, Strawberry exposition in the department of cultivated plants of the Main Botanical Garden, 180 (2020)

7. N. S. Danilova, S. Z. Borisova, A. Yu. Romanova, A. E. Petrova, B. A. Karpel, T. Yu. Rogozhina, E. I. Nazarova, Cadastre of introducers of Yakutia: Plants of the natural flora of Yakutia (Moscow, Science/Interperiodics, 2001)

8. M. K. Gavrilova, Climate of Central Yakutia (Yakutsk. Yakut publ. House, 1973)

9. A. A. Zubov, D. B. Shokaeva, Program and methodology of variety study of fruit, berry and nut crops (Orel, Publishing House of the All-Russian Scientific Research Institute of Fruit Crop Breeding, 1999)

10. V. I. Belevtsova, Introduction of wild East-Asian strawberries in Central Yakutia, in Proceedings of the International Scientific and Practical Conference: Unconventional and rare plants, natural compounds and prospects for their use, VII International Symposium, I, Belgorod: Publ. house "Polyterra" (2006)

11. G. F. Govorova, D. N. Govorov, Strawberry: the past, present and future (Moscow, Rosinformagrotech, 2004) 